\title{
Exposure to vitamin D from fortified margarine during fetal life and later risk of pre-eclampsia: the D-tect Study
}

\author{
Maria Stougaard ${ }^{1, *}$, Peter Damm ${ }^{2,3}$, Peder Frederiksen ${ }^{1}$, Ramune Jacobsen ${ }^{1,4}$ and \\ Berit L Heitmann ${ }^{1,5,6}$ \\ ${ }^{1}$ Research Unit for Dietary Studies at Parker Institute and Department of Clinical Epidemiology, Bispebjerg and \\ Frederiksberg Hospital, Nordre Fasanvej 57, Hovedvejen, Entranc 5, 2000 Frederiksberg, Denmark: ${ }^{2}$ Department \\ of Obstetrics, Rigshospitalet, Copenhagen, Denmark: ${ }^{3}$ Institute of Clinical Medicine, Faculty of Health and Medical \\ Sciences, University of Copenhagen, Copenhagen, Denmark: ${ }^{4}$ Research Unit for Chronic Conditions, Bispebjerg and \\ Frederiksberg Hospital, The Capital Region, Copenhagen, Denmark: ${ }^{5}$ National Institute of Public Health, University

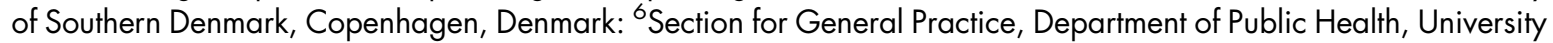 \\ of Copenhagen, Copenhagen, Denmark
}

Submitted 28 January 2017: Final revision received 31 August 2017: Accepted 11 September 2017: First published online 20 December 2017

\begin{abstract}
Objective: To examine if fetal exposure to a small dosage of extra vitamin D from food fortification was associated with a decrease in the risk of pre-eclampsia later in life.

Design: Cancellation of the mandatory vitamin D fortification of margarine in 1985 created a societal experiment, with entire adjacent birth cohorts exposed or unexposed to extra vitamin D during fetal development. The Danish national medical health registries allowed the identification of pre-eclampsia cases later in life among all exposed and unexposed female individuals.

Setting: Denmark.

Subjects: Women born between June 1983 and August 1988, who gave birth to their first child at age $14.5-27 \cdot 5$ years ( $n 32621$ ).

Results: OR (95\% CI) for pre-eclampsia among women exposed $v$. unexposed to extra vitamin D from fortification during fetal development was $0 \cdot 86(0 \cdot 76,0 \cdot 97)$. Exposure to extra vitamin D was associated with further reduced odds of pre-eclampsia $(0.49(0.34,0.72))$ among current smokers, but not among former smokers and non-smokers.

Conclusions: Additional vitamin D in fetal life from food fortification seems to reduce the risk of pre-eclampsia later in life. The risk reduction may be particularly strong among women who smoke during pregnancy.
\end{abstract}

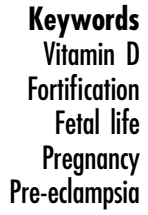

Keywords ortification

Fetal life Pre-eclampsia
Hypertension is the most common medical problem in pregnancy, occurring in up to $15 \%$ of all pregnancies ${ }^{(1)}$. Pre-eclampsia is a severe pregnancy-related hypertensive syndrome characterized by hypertension and proteinuria ${ }^{(2)}$. Pre-eclampsia develops from mid-pregnancy and affects 3$5 \%$ of all pregnancies. The incidence rate is $1 \cdot 5$ - to $2 \cdot 0$-fold higher among first-time pregnancies compared with subsequent pregnancies ${ }^{(3-5)}$. On rare occasions pre-eclampsia can develop into eclampsia or haemolysis, elevated liver enzymes, low platelets (HELLP) syndrome, and other severe complications ${ }^{(2,6)}$. Pre-eclampsia is associated with increased morbidity and mortality in both the pregnant women and the offspring, with long-term negative health consequences such as CVD and diabetes ${ }^{(3,7-11)}$.

The aetiology and pathophysiology of pre-eclampsia have not been fully elucidated. Abnormal placentation, oxidative stress and thrombosis are all thought to contribute to the development of pre-eclampsia ${ }^{(12)}$. Young and old age, high BMI, multiple pregnancies, autoimmune and infectious diseases, family history of pre-eclampsia and male offspring, as well as low maternal socioeconomic status ${ }^{(13)}$, are described risk factors associated with pre-eclampsia ${ }^{(3,14-16)}$. Physical activity before and early in pregnancy, as well as smoking during pregnancy was shown to reduce the risk of pre-eclampsia ${ }^{(17,18)}$. Sufficient vitamin D intake during pregnancy has also been suggested to reduce the risk of pre-eclampsia ${ }^{(19,20)}$.

Vitamin D is a complex of fat-soluble secosteroids involved in $\mathrm{Ca}$ and $\mathrm{P}$ homeostasis and in the development of the skeleton. In addition, vitamin $\mathrm{D}$ also has nonskeletal functions that include immunomodulatory and anti-inflammatory properties, and has also been found to affect hormone secretion, cardiovascular function and blood pressure ${ }^{(13)}$. 
It is well established that the fetal environment plays an important role in later health and disease risk ${ }^{(21)}$. During pregnancy, growth and development of the fetus depend on the nutritional status of the pregnant mother and on the capability of the placenta to exchange nutrients, such as vitamin $\mathrm{D}$, between the pregnant woman and fetus ${ }^{(22)}$. Vitamin D insufficiency is common among otherwise healthy pregnant women ${ }^{(23,24)}$ and, as maternal and fetal vitamin D statuses are strongly correlated, there is increasing interest in maternal vitamin $\mathrm{D}$ insufficiency during pregnancy and its potential long-term health consequences for the offspring ${ }^{(25)}$.

So far, only one previous study has examined if extra vitamin D from supplementation early in life influences the risk of developing pre-eclampsia later in life ${ }^{(26)}$. The study followed 2969 women in Northern Finland born in 1966 who, in their first year of life, regularly or irregularly, received up to $50 \mu \mathrm{g}$ of vitamin D daily, as well as women who did not receive any supplementation. After adjusting for biological, social and medical characteristics, a $50 \%$ risk reduction of pre-eclampsia was found among women who had regularly received vitamin D supplementation during infancy, compared with those who received irregular or no supplementation ${ }^{(26)}$.

Studies examining the importance of fetal nutrition on health later in life are time-consuming and may involve substantial costs and logistic difficulties. Conducting 'societal experiments' (e.g. fetal undernutrition during famines) has been widely used in exploring early origins of adult diseases in a cost-effective manner ${ }^{(27,28)}$. The present study is based on a societal experiment around margarine fortification with vitamin D in Denmark. In June 1985, mandatory fortification of margarine with vitamin D, which started in the 1930s and supplied on average $13 \%$ (3-29\%) of all dietary intake of vitamin D to adult Danes $^{(29)}$, was abandoned ${ }^{(30-33)}$. Consequently, individuals born before 1985 were exposed to vitamin D from fortified margarine during fetal development and individuals born after the cancellation were not.

The purpose of the present study was to examine if fetal exposure to extra vitamin D from fortified margarine lowered the risk of pre-eclampsia later in life.

\section{Methods and materials}

\section{Data sources}

Information about the study population was retrieved from the Danish Civil Registration System (CSR); information on the pregnant women and their newborns was retrieved from the Danish Medical Birth Registry (MBR); and the presence of pre-eclampsia in the pregnant women was identified from the Danish National Patient Registry (DNPR). Age of delivery was calculated based on information on maternal day of birth retrieved from the CSR and information on date of delivery retrieved from the MBR.
The CSR was established in April 1968 and has since registered all people alive and living in Denmark with a 10-digit civil person register (CPR) number. The CPR number enables linkage of individual information from different nationwide registers and large clinical databases $^{(34)}$. The MBR was established in 1973 and contains information obtained during the antenatal care visits for all women with permanent residence in Denmark ${ }^{(35)}$. The DNPR was established in 1977, and records information on all patients discharged from Danish non-psychiatric hospitals since 1977 and emergency and outpatient departments since $1995^{(36)}$.

\section{Definition of outcome}

Since 1994, the diseases collected into the DNPR have been coded according to the International Statistical Classification of Diseases and Related Health Problems, 10th Revision (ICD-10). The present study included the following ICD-10 codes: gestational hypertension (code O13.9); mild to moderate pre-eclampsia (code O14.0); severe pre-eclampsia (code O14.1); HELLP syndrome (code O14.2); pre-eclampsia, unspecified (code O14.9); eclampsia in pregnancy (code O15.0); eclampsia during delivery (code O15.2); and eclampsia, unspecified as to time period (O15.9). The included diagnoses were categorized into three groups (Table 1). In cases where a woman had been diagnosed with more than one of the included diagnoses during the included pregnancy, only the diagnosis indicating the most severe form of pre-eclampsia was assigned.

\section{Study population}

In Denmark, it was mandatory to fortify margarine with vitamin D $(1.25 \mu \mathrm{g} / 100 \mathrm{~g})$ until June 1985. A 15-month 'wash-out period', including the full 9 months of pregnancy and additional 6 months to secure that the fortified margarine was no longer available at home or in stores, was introduced from June 1985 to September 1986. Therefore, the cohort of women born in the two years immediately before June 1985, born from June 1983 to May 1985, was defined as exposed to extra vitamin D during fetal

Table 1 Description of gestational hypertension, pre-eclampsia and eclampsia by International Statistical Classification of Diseases and Related Health Problems 10th Revision (ICD10) code and grouping

\begin{tabular}{ll}
\hline Classification & ICD10 code with description \\
\hline Group 1 & Gestational hypertension (code O13.9) \\
Group 2 & Mild to moderate pre-eclampsia (code O14.0) \\
Group 3 & Pre-eclampsia, unspecified (code O14.9) \\
& Severe pre-eclampsia (code O14.1) \\
& HELLP syndrome (code O14.2) \\
& Eclampsia in pregnancy (code O15.0) \\
& Eclampsia in labour (code O15.2) \\
& Eclampsia, unspecified as to time period (O15.9)
\end{tabular}

HELLP, haemolysis, elevated liver enzymes, low platelets. 
development and the cohort of women born after the washout period, born from September 1986 to August 1988, was defined as unexposed. From June 1983 to August 1988, 162397 females were born in Denmark; among these females, 112311 gave birth. Those born during the 'washout period' were excluded from the study ( $n$ 27003), reducing the number of births to 85308. In the present study, the number of births by women who, due to the mandatory margarine fortification, were exposed to additional vitamin D during fetal life was 52873 . The number of births by women unexposed to the extra vitamin D during fetal development was 32435 . Women in the exposed cohort were frequently older and more often multiparous; therefore, the number of births among the exposed women was higher compared with the unexposed. As incidence of pre-eclampsia is higher in first-time pregnancies, the study population was restricted to nulliparous women ${ }^{(3-5)}$. Based on maternal day of birth and date of delivery, the study population was restricted to women giving birth at age 14.5 to 27.5 years and delivering their offspring after gestational week 22 to ensure similar age in both cohorts. Newborns with birth weight of $0 \mathrm{~g}$ and very young women, as well as very young women with pre-pregnancy BMI below the established cut-offs for this age group ${ }^{(37)}$, were also excluded, resulting in 16081 births in the exposed group and 17168 births in the unexposed group. Finally, those with missing information on singleton and multiple births, offspring birth weight or gender, smoking status or gestational age were also excluded. The final groups consisted of 15733 exposed nulliparous women and 16888 unexposed nulliparous women. A flowchart of the study population is illustrated in Fig. 1. The sampling is illustrated in Fig. 2. The nulliparous women exposed to the vitamin D fortification in utero gave birth between December 1997 and December 2012; nulliparous women unexposed to the vitamin D fortification in utero gave birth between March 2001 and March 2016.

\section{Variables}

Information on pre-pregnancy BMI, smoking status, singleton and multiple births and gender of the newborn was retrieved from the MBR.

Pre-pregnancy BMI has been included in the MBR since 2004. At the first antenatal visit, normally taking place during the first trimester, the woman's BMI is calculated based on self-reported information. Applying International Obesity Task Force standards for adolescent $\mathrm{BMI}^{(37,38)}$, women with pre-pregnancy BMI below $15 \cdot 46 \mathrm{~kg} / \mathrm{m}^{2}$ were excluded ${ }^{(37)}$. Obesity defined as $\mathrm{BMI} \geq 30 \cdot 0 \mathrm{~kg} / \mathrm{m}^{2}$ is an established risk factor for pre-eclampsia ${ }^{(39,40)}$ and the association between pre-pregnancy BMI and pre-eclampsia may not be linear ${ }^{(41)}$. Therefore, we categorized pre-pregnancy BMI into the four following categories: $<18.5 \mathrm{~kg} / \mathrm{m}^{2}, 18.5-24.9 \mathrm{~kg} / \mathrm{m}^{2}$, $25 \cdot 0-29 \cdot 9 \mathrm{~kg} / \mathrm{m}^{2}$ and $\geq 30 \cdot 0 \mathrm{~kg} / \mathrm{m}^{2}$.

Information on smoking habits of the pregnant women has been collected into the MBR since 1997. This information was grouped into three categories: current smokers, former smokers (women who stopped smoking during or after the first trimester in the current pregnancy) and non-smokers.

The Danish national guidelines regarding late term definition were changed in $2009^{(42)}$. Therefore, to make cohorts comparable with regard to term of birth, we categorized gestational age at birth by weeks + days, rather than pre-term, full-term and post-term categories. The following seven categories were constructed: (i) $<37$, (ii) $37+0$ to $37+6$, (iii) $38+0$ to $38+6$, (iv) $39+0$ to $39+6$, (v) $40+0$ to $40+6$, (vi) $41+0$ to $41+6$ and (vii) $\geq 42$ complete weeks of gestation.

\section{Statistical analyses}

Differences between exposed and unexposed women were tested by the $\chi^{2}$ test for categorical data and the Mann-Whitney rank-sum test for skewed continuous data. The age restriction caused the age distribution to be skewed a priori; therefore, a formal statistical test of normality was unnecessary.

The association between exposure status and risk of preeclampsia later in life was examined by logistic regression, generating OR with $95 \% \mathrm{CI}$. The following confounders were included into the multivariate regression models: woman's age at delivery, smoking habits, and singleton and multiple pregnancies. These confounders were hypothesized to be related to pre-eclampsia risk $^{(3,16,17,43)}$ or to vitamin D levels during gestation ${ }^{(20,26,44)}$. The main analyses were not adjusted for pre-pregnancy BMI; this information is available only from 2004 and forwards, thus adjustment would have made exposed and unexposed women incomparable in terms of age. To explore the impact of pre-pregnancy BMI, sensitivity analyses were conducted as sub-analyses including only those women who had information on pre-pregnancy BMI; the analyses in this subgroup were adjusted for pre-pregnancy BMI.

Earlier studies have found that smoking during pregnancy may protect against development of pre-eclampsia. Furthermore, smoking has previously been associated with vitamin D levels ${ }^{(45,46)}$. Interactions between smoking and vitamin D exposure status in relation to pre-eclampsia risk were analysed by conducting the models stratified by women's smoking status. Additionally, interactions between exposure status and women's age at delivery $^{(3,15)}$, as well as between exposure status and prepregnancy $\mathrm{BMI}^{(14)}$, were tested using likelihood ratio tests.

Data were analysed using the statistical software package Stata version 13; $P<0.05$ was considered statistically significant.

\section{Ethics}

The study was conducted in accordance with Danish law and approved by the Danish Data Protection Agency (journal number 2012-41-1156) providing permission to access the relevant registries. The study was based on 


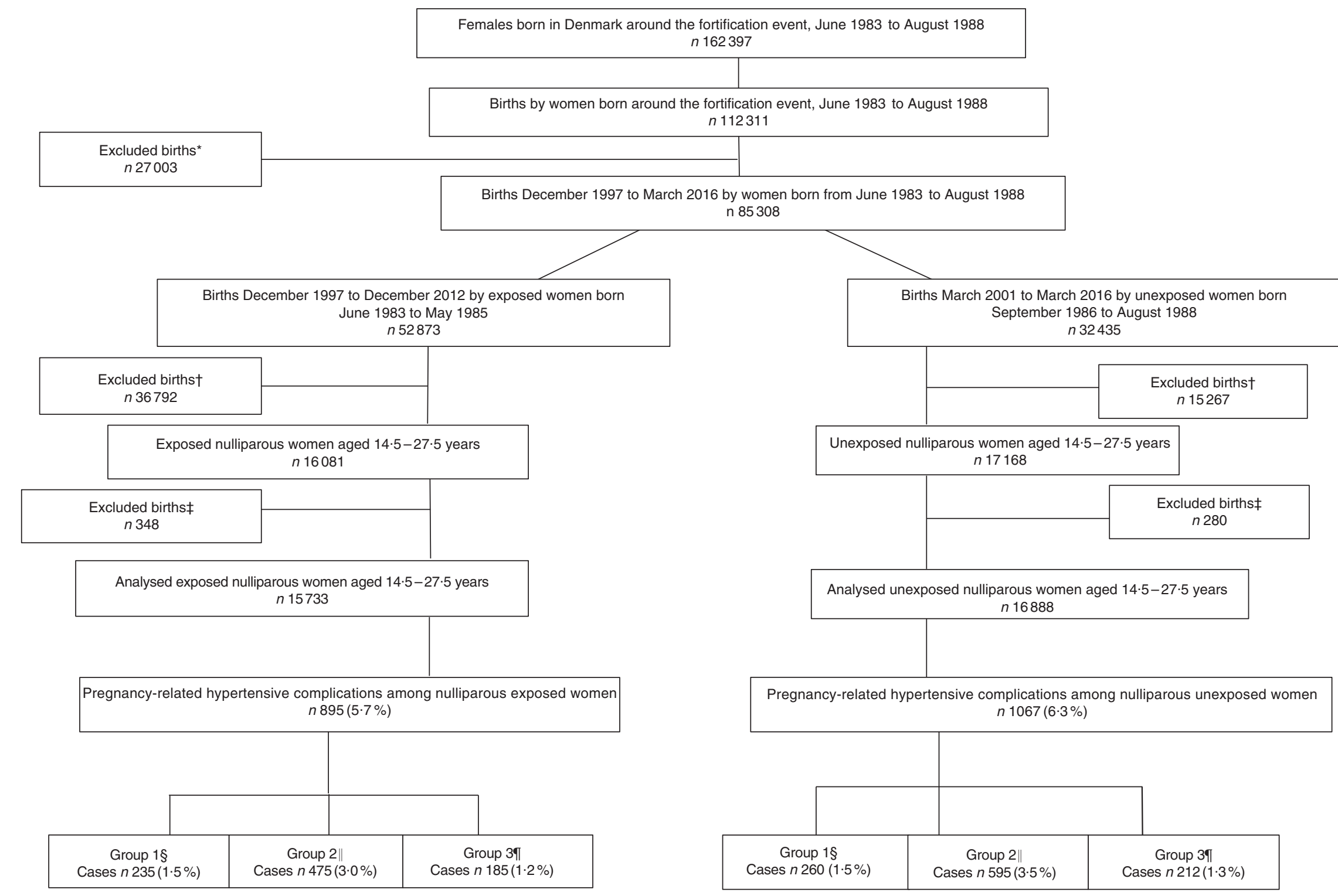

Fig. 1 Flowchart of the study population of women born between June 1983 and August 1988, who gave birth to their first child at age 14.5 to 27.5 years. *Women excluded because they gave birth during the 15-month wash-out period from June 1985 to September 1986. †Births where the woman was either below 14.5 or above 27.5 years of age, the offspring's birth weight was misclassified, gestational weeks was $<22$ weeks or pre-pregnancy BMI was $<15.46 \mathrm{~kg} / \mathrm{m}^{2}$. \#Excluded due to missing information on age at delivery, smoking habits, singleton and multiple births, gestational age at delivery or offspring gender. §Group 1, gestational hypertension; ICD-10 code: O13.9. \|Group 2, mild to moderate and unspecified pre-eclampsia; ICD-10 codes: O14.0 and 014.9. IGroup 3, severe pre-eclampsia, HELLP syndrome and eclampsia; ICD-10 codes: O14.1, O14.2 and O15.0 (ICD-10, International Statistical Classification of Diseases and Related Health Problems 10th Revision; HELLP, haemolysis, elevated liver enzymes, low platelets) 

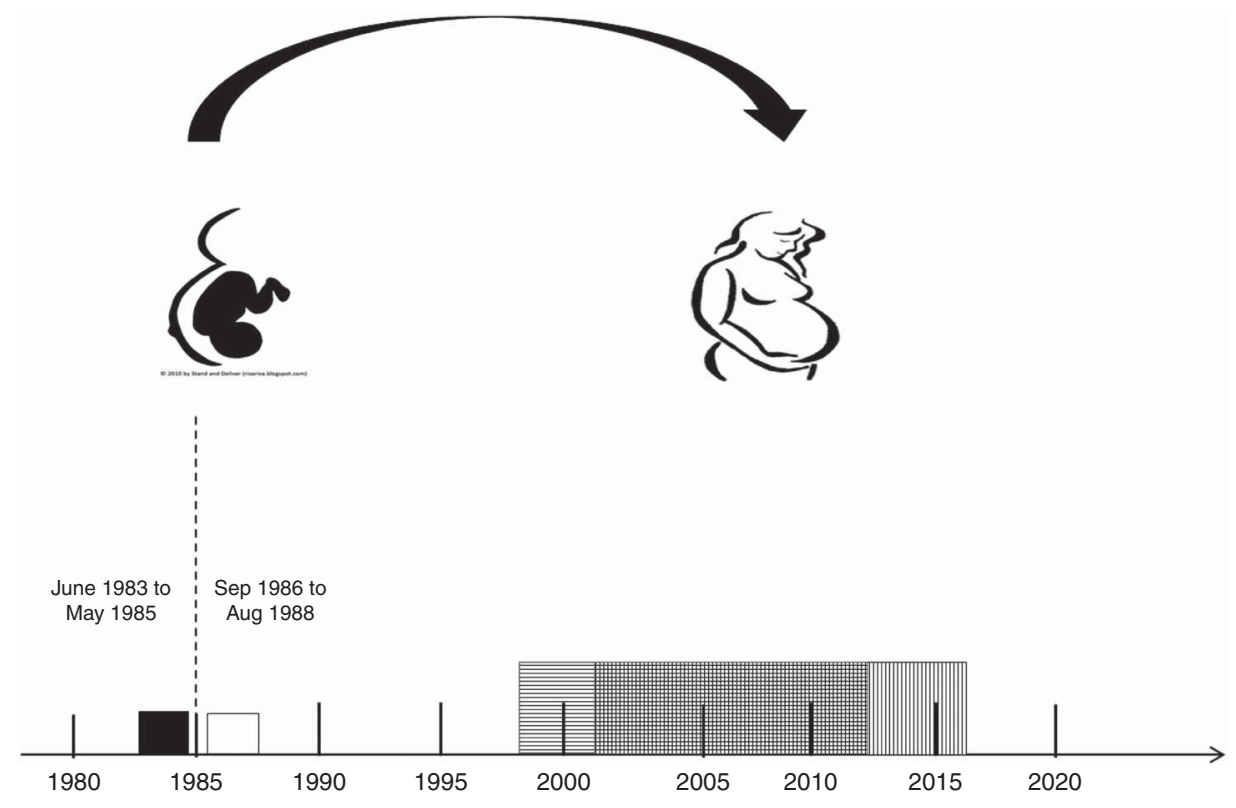

Fig. 2 Sampling of the study population of women born between June 1983 and August 1988, who gave birth to their first child at age 14.5 to 27.5 years. $(\square)$, exposed women born between June 1983 and May 1985; $(\square)$, unexposed women born between September 1986 to August 1988; (-- - - ), the 'wash-out' period from June 1985 to September 1986. The exposed women gave birth between December 1997 and December 2012 (目); the unexposed women gave birth from March 2001 to March 2016 (四)

already collected data, the use of which does not require ethical approval.

\section{Results}

The proportion of births with pre-eclampsia, including cases of eclampsia (group 2 and 3; Table 1), among the nulliparous women exposed or unexposed to vitamin D fortification during fetal life was $4 \cdot 2 \%(660 / 15733)$ and $4 \cdot 8 \%(807 / 16888)$, respectively. Despite the age restrictions, the age at delivery was slightly higher for the exposed women compared with unexposed; the median (5th-95th percentile) age being $24.9(19 \cdot 5-27 \cdot 3)$ and $24.7(19 \cdot 4-27 \cdot 3)$ years, respectively $(P<0 \cdot 0001)$. Furthermore, exposed compared with unexposed women were more often current smokers (18.9 v. 15.8\%, respectively) and more often gave birth at late gestational age (6.1 v. 3.6\%, respectively). Moreover, exposed compared with unexposed women more often had a $\mathrm{BMI}<18.5 \mathrm{~kg} / \mathrm{m}^{2}(4.4 v .5 \cdot 2 \%$, respectively) and less often had a BMI $\geq 30.0 \mathrm{~kg} / \mathrm{m}^{2}(13.6 v$. $13.9 \%$, respectively). Other characteristics were not different between exposed and unexposed women (Table 2).

Overall, there was a lower risk of pregnancy-related hypertensive complications among women who were exposed to extra vitamin D in fetal development compared with the unexposed women (Table 3). However, in the analyses stratified by outcome severity, the exposure effect was observed only among women diagnosed with mild to moderate and unspecified pre-eclampsia. No significant associations were found for the diagnoses of gestational hypertension, severe pre-eclampsia, HELLP syndrome and eclampsia. Adjusting for women's age at delivery, smoking habits, singleton and multiple births and offspring gender gave essentially similar results (Table 3). The estimates for the covariates are listed in the online supplementary material, Supplemental Table 1.

The interaction between exposure to vitamin $\mathrm{D}$ and smoking status was significant $\left(\chi^{2}=11.82 ; \quad \mathrm{df}=2\right.$; $P=0.003)$ and stratifying analyses on smoking status revealed that the strongest association between in utero vitamin D exposure status and pre-eclampsia risk was seen among current smokers, where the risk of all types of pre-eclampsia was halved or more for the exposed women compared with unexposed ones (Table 4).

Pre-pregnancy BMI measurements were available only for a sub-population of 13640 in the exposed group and a sub-population of 14871 in the unexposed group. Sensitivity analyses in these sub-populations were restricted to women of similar age (age 20-27 years) and were adjusted for pre-pregnancy BMI; the results of these analyses (Table 5) were similar to the main findings.

Interactions between exposure status and women's age at delivery $\left(\chi^{2}=3.58 ; \mathrm{df}=4 ; P=0.47\right)$, as well as between exposure status and pre-pregnancy BMI, were not significant $\left(\chi^{2}=0 \cdot 77 ; \mathrm{df}=3 ; P=0 \cdot 86\right)$.

\section{Discussion}

In accordance with the incidence of pre-eclampsia worldwide, approximately $4.5 \%$ of the women in our sample were diagnosed with pre-eclampsia of different severity ${ }^{(3)}$. The present study found that the risk of mild to 
Table 2 Characteristics of women and their offspring, according to whether the woman was exposed to extra vitamin $D$ from food fortification in fetal life or not; women born between June 1983 and August 1988, who gave birth to their first child at age 14.5 to 27.5 years

\begin{tabular}{|c|c|c|c|c|c|c|c|}
\hline \multirow[b]{2}{*}{ Characteristic } & \multicolumn{3}{|c|}{ Exposed } & \multicolumn{3}{|c|}{ Unexposed } & \multirow[b]{2}{*}{$P$ value } \\
\hline & $N$ & Median & $\begin{array}{l}\text { 5th-95th } \\
\text { percentile }\end{array}$ & $N$ & Median & $\begin{array}{l}\text { 5th-95th } \\
\text { percentile }\end{array}$ & \\
\hline \multirow[t]{2}{*}{ Age at delivery* (years) } & 15733 & $24 \cdot 9$ & $19 \cdot 5-27 \cdot 3$ & 16888 & $24 \cdot 7$ & $19 \cdot 4-27 \cdot 3$ & $<0.0001$ \\
\hline & & $n$ & $\%$ & & $n$ & $\%$ & \\
\hline Outcome† & 15733 & & & 16888 & & & \\
\hline Gestational hypertension $\ddagger$ & & 235 & 1.5 & & 260 & 1.5 & 0.7 \\
\hline Mild to moderate and unspecified pre-eclampsia§ & & 475 & $3 \cdot 0$ & & 595 & 3.5 & 0.01 \\
\hline $\begin{array}{l}\text { Severe pre-eclampsia, HELLP syndrome and } \\
\text { eclampsiaף }\end{array}$ & & 185 & $1 \cdot 2$ & & 212 & $1 \cdot 3$ & 0.5 \\
\hline All above & & 895 & $5 \cdot 7$ & & 1067 & $6 \cdot 3$ & 0.02 \\
\hline Pre-pregnancy BMI†, \| & 13640 & & & 14781 & & & 0.02 \\
\hline$<18.5 \mathrm{~kg} / \mathrm{m}^{2}$ & & 609 & 4.4 & & 772 & $5 \cdot 2$ & \\
\hline $18.5-24.9 \mathrm{~kg} / \mathrm{m}^{2}$ & & 8251 & $60 \cdot 5$ & & 8821 & $59 \cdot 7$ & \\
\hline $25.5-29.9 \mathrm{~kg} / \mathrm{m}^{2}$ & & 2930 & 21.5 & & 3127 & $21 \cdot 2$ & \\
\hline$\geq 30.0 \mathrm{~kg} / \mathrm{m}^{2}$ & & 1850 & $13 \cdot 6$ & & 2031 & 13.9 & \\
\hline Smoking status during pregnancy† & 15733 & & & 16888 & & & $<0.0001$ \\
\hline Current smoker & & 2968 & $18 \cdot 9$ & & 2670 & $15 \cdot 8$ & \\
\hline Former smoker & & 799 & $5 \cdot 1$ & & 969 & $5 \cdot 7$ & \\
\hline Non-smoker & & 11966 & $76 \cdot 0$ & & 13249 & 78.5 & \\
\hline Singleton or multiple pregnancy† & 15733 & & & 16888 & & & 0.38 \\
\hline Singleton & & 15547 & $98 \cdot 8$ & & 16670 & $98 \cdot 7$ & \\
\hline Multiple & & 186 & 1.2 & & 218 & 1.3 & \\
\hline Gestational age at delivery (weeks) $\dagger$ & 15733 & & & 16888 & & & $<0.0001$ \\
\hline$<37$ & & 1120 & $7 \cdot 1$ & & 1185 & $7 \cdot 0$ & \\
\hline $37+0$ to $37+6$ & & 822 & $5 \cdot 2$ & & 866 & $5 \cdot 1$ & \\
\hline $38+0$ to $38+6$ & & 1950 & $12 \cdot 4$ & & 2026 & $12 \cdot 0$ & \\
\hline $39+0$ to $39+6$ & & 3362 & 21.4 & & 3538 & $21 \cdot 0$ & \\
\hline $40+0$ to $40+6$ & & 4419 & $28 \cdot 1$ & & 4946 & $29 \cdot 3$ & \\
\hline $41+0$ to $41+6$ & & 3092 & 19.7 & & 3712 & 22.0 & \\
\hline$\geq 42$ & & 968 & $6 \cdot 1$ & & 615 & 3.6 & \\
\hline Offspring's gender† & 15733 & & & 16888 & & & 0.05 \\
\hline Female & & 7742 & $49 \cdot 2$ & & 8151 & $48 \cdot 3$ & \\
\hline Male & & 7991 & $50 \cdot 8$ & & 8737 & $51 \cdot 7$ & \\
\hline
\end{tabular}

HELLP, haemolysis, elevated liver enzymes, low platelets; ICD-10, International Statistical Classification of Diseases and Related Health Problems 10th Revision.

*Tested by the Mann-Whitney rank-sum test.

†Tested by the $X^{2}$ test.

†ICD-10 code: O13.9.

§ICD-10 codes: O14.0 and O14.9

IICD-10 codes: O14.1, O14.2 and O15.0

|| Information available only from 2004 and forwards.

Table 3 Crude and adjusted odds for pre-eclampsia among women exposed to extra vitamin D in fetal life; women born between June 1983 and August 1988, who gave birth to their first child at age 14.5 to 27.5 years

\begin{tabular}{|c|c|c|c|c|c|}
\hline \multirow[b]{2}{*}{ Outcome } & \multirow[b]{2}{*}{$N_{\text {cases }}$} & \multicolumn{2}{|c|}{ Crude model } & \multicolumn{2}{|c|}{ Adjusted model ${ }^{*}$} \\
\hline & & OR & $95 \% \mathrm{Cl}$ & OR & $95 \% \mathrm{Cl}$ \\
\hline Gestational hypertension $\dagger$ & 495 & 0.97 & $0.81,1.16$ & 0.96 & $0.81,1 \cdot 15$ \\
\hline Mild to moderate and unspecified pre-eclampsiał & 1070 & 0.85 & $0.75,0.96$ & 0.86 & $0.76,0.97$ \\
\hline Severe pre-eclampsia, HELLP syndrome and eclampsiaT & 397 & 0.94 & $0.77,1.14$ & 0.95 & $0.78,1.16$ \\
\hline All above & 1962 & 0.89 & $0.82,0.98$ & 0.90 & $0.82,0.99$ \\
\hline
\end{tabular}

HELLP, haemolysis, elevated liver enzymes, low platelets; ICD-10, International Statistical Classification of Diseases and Related Health Problems 10th Revision.

${ }^{*}$ Adjusted for age at delivery, maternal smoking status, and singleton or multiple births.

†ICD-10 code: O13.9.

IICD-10 codes: 014.0 and 014.9.

§ICD-10 codes: O14.1, O14.2 and O15.0.

moderate and unspecified pre-eclampsia was lower in those nulliparous women who were exposed to small amounts of additional vitamin $\mathrm{D}$ from food fortification during their fetal development, suggesting that vitamin D may have exerted programming effects on the risk of pregnancy complications later in life. Our results also indicate that the effects of vitamin D on the risk of pre-eclampsia were most obvious among women who smoked during pregnancy. 
Table 4 Crude and adjusted odds for pre-eclampsia among smoking and non-smoking women exposed to extra vitamin D from fortification during fetal life; women born between June 1983 and August 1988, who gave birth to their first child at age 14.5 to 27.5 years

\begin{tabular}{|c|c|c|c|c|c|c|c|c|c|c|c|c|c|c|c|}
\hline \multirow[b]{3}{*}{ Outcome } & \multicolumn{5}{|c|}{ Non-smokers } & \multicolumn{5}{|c|}{ Former smokers } & \multicolumn{5}{|c|}{ Current smokers } \\
\hline & \multirow[b]{2}{*}{$N_{\text {cases }}$} & \multicolumn{2}{|c|}{ Crude model } & \multicolumn{2}{|c|}{$\begin{array}{c}\text { Adjusted } \\
\text { model }^{*}\end{array}$} & \multirow[b]{2}{*}{$N_{\text {cases }}$} & \multicolumn{2}{|c|}{ Crude model } & \multicolumn{2}{|c|}{$\begin{array}{c}\text { Adjusted } \\
\text { model }^{*}\end{array}$} & \multirow[b]{2}{*}{$N_{\text {cases }}$} & \multicolumn{2}{|c|}{ Crude model } & \multicolumn{2}{|c|}{$\begin{array}{c}\text { Adjusted } \\
\text { model }^{*}\end{array}$} \\
\hline & & OR & $95 \% \mathrm{Cl}$ & OR & $95 \% \mathrm{Cl}$ & & OR & $95 \% \mathrm{Cl}$ & OR & $95 \% \mathrm{Cl}$ & & OR & $95 \% \mathrm{Cl}$ & OR & $95 \% \mathrm{Cl}$ \\
\hline Gestational hypertension $\dagger$ & 401 & 0.99 & $0.81,1.20$ & 0.97 & $0.80,1 \cdot 19$ & 36 & 0.86 & $0.44,1.69$ & 0.84 & $0.43,1.65$ & 58 & 1.00 & $0.60,1.67$ & 0.97 & $0.59,1.64$ \\
\hline $\begin{array}{l}\text { Mild to moderate and } \\
\text { unspecified pre- } \\
\text { eclampsiał }\end{array}$ & 892 & 0.93 & $0.81,1.06$ & 0.92 & $0.81,1.05$ & 62 & 0.87 & $0.52,1.46$ & 0.89 & $0.53,1.50$ & 116 & 0.50 & $0.34,0.74$ & 0.49 & $0.34,0.72$ \\
\hline $\begin{array}{l}\text { Severe pre-eclampsia, } \\
\text { HELLP syndrome and } \\
\text { eclampsia§ }\end{array}$ & 335 & 1.04 & $0.84,1.29$ & 1.04 & $0.84,1.29$ & 17 & 1.37 & $0.52,3.56$ & 1.40 & $0.53,3.65$ & 45 & 0.40 & $0.21,0.76$ & 0.41 & $0.22,0.76$ \\
\hline All above & 1628 & 0.96 & $0.87,1.07$ & 0.96 & $0.87,1.06$ & 115 & 0.93 & $0.63,1.36$ & 0.93 & $0.64,1.37$ & 219 & 0.58 & $0.44,0.76$ & 0.56 & $0.43,0.74$ \\
\hline
\end{tabular}

HELLP, haemolysis, elevated liver enzymes, low platelets; ICD-10, International Statistical Classification of Diseases and Related Health Problems 10th Revision.

${ }^{*}$ Adjusted for age at delivery, and singleton and multiple births.

†ICD-10 code: 013.9 .

IICD-10 codes: 014.0 and 014.9 .

§ICD-10 codes: O14.1, O14.2 and O15.0.

Table 5 Crude and adjusted odds for pre-eclampsia among women exposed $v$. unexposed to extra vitamin $D$ from fortification during fetal life, restricted to include only those women with information on pre-pregnancy BMl; women born between June 1983 and August 1988 , who gave birth to their first child at age 14.5 to 27.5 years

\begin{tabular}{|c|c|c|c|c|c|}
\hline \multirow[b]{2}{*}{ Outcome } & \multirow[b]{2}{*}{$N_{\text {cases }}$} & \multicolumn{2}{|c|}{ Crude model } & \multicolumn{2}{|c|}{ Adjusted model ${ }^{*}$} \\
\hline & & OR & $95 \% \mathrm{Cl}$ & OR & $95 \% \mathrm{Cl}$ \\
\hline Gestational hypertension $†$ & 464 & 0.99 & $0.83,1.19$ & 0.99 & $0.82,1.19$ \\
\hline Mild to moderate and unspecified pre-eclampsiał & 972 & 0.86 & $0.76,0.98$ & 0.86 & $0.76,0.99$ \\
\hline Severe pre-eclampsia, HELLP syndrome and eclampsia§ & 355 & 0.95 & $0.77,1.17$ & 0.96 & $0.78,1.19$ \\
\hline All above & 1791 & 0.91 & $0.82,1.00$ & 0.91 & $0.83,1.01$ \\
\hline
\end{tabular}

HELLP, haemolysis, elevated liver enzymes, low platelets; ICD-10, International Statistical Classification of Diseases and Related Health Problems 10th Revision.

*Adjusted for age at delivery, maternal smoking status, pre-pregnancy BMI, and singleton or multiple births.

†ICD-10 code: 013.9 .

IICD-10 codes: 014.0 and 014.9 .

§ICD-10 codes: O14.1, O14.2 and O15.0.

Our findings are in accordance with those of Hypponen et $a{ }^{(26)}$, who found that the risk of pre-eclampsia was halved among the women who regularly received vitamin D supplementation in their first year of life. The supplemented dose in the study by Hypponen et al. ${ }^{(26)}$ corresponded to $50 \mu \mathrm{g}$ vitamin $\mathrm{D} / \mathrm{d}$. In our study, the extra daily vitamin D doses delivered with fortification were much smaller. Based on our calculations, the dosage could have been about $0.5-0.6 \mu \mathrm{g}$ of extra vitamin $\mathrm{D}$ daily for the women; for the fetus, the dosages probably were even lower ${ }^{(29,47)}$. It is important to note that while we examined the influence of vitamin D exposure during fetal life, Hypponen et al. ${ }^{(26)}$ examined the influence of vitamin D supplementation during the child's first year of life. Other previously conducted studies, including one from our group, showed that vitamin D supplementation dosage and timing were important to prevent type 1 diabetes, where supplementation in infancy with high dosages was shown to have a protective effect ${ }^{(44)}$ while exposure to low-extra dosages from fortification throughout fetal development was not ${ }^{(48)}$. The dose and timing of the extra vitamin $\mathrm{D}$ seem to be of less importance in relation to prevention of pre-eclampsia ${ }^{(26)}$.
Notably, our study and the study by Hypponen et al. ${ }^{(26)}$ utilized different study designs. Hypponen et al. ${ }^{(26)}$ conducted a classical cohort study, where information on vitamin D supplementation during the child's first years of life was collected. The female offspring were followed for pre-eclampsia outcome in their own pregnancies. Such a study takes a long time, many resources and is difficult logistically. The societal experiment introducing a termination of the mandatory vitamin $\mathrm{D}$ fortification programme in Denmark provided us with a unique opportunity to investigate research questions similar to those of Hypponen et al. ${ }^{(26)}$ quickly and cost-effectively, and without the necessity to address each woman's individual vitamin D intake. However, the societal experiment design is prone to various biases, which are outlined below. On the other hand, in the study by Hypponen et al. ${ }^{(26)}$, vitamin D intake is prone to recall bias. Further research confirming our and Hypponen et al.'s ${ }^{(26)}$ findings is needed. Specifically, a randomized controlled trial would be needed to firmly conclude on causal relationships between fetal vitamin D exposure and pre-eclampsia risk later in life. Such a trial, however, would have to track offspring from quite large groups of in utero vitamin D-supplemented and 
non-supplemented women for two or three decades after the supplementation actually took place. We would recommend that, before conducting a randomized controlled trial, an effort is made to identify already existing cohorts, similar to the one used in the study by Hypponen et $a l^{(26)}$, with information on fetal exposure to extra vitamin D. An alternative solution could be an observational study, with objective vitamin D biomarker measurement in fetal or neonatal blood, coupled with register information on preeclampsia incidence later in life. In fact, such a study is currently being conducted by our research group.

In Denmark, since 1981 neonatal blood has been routinely collected from all newborns $48-72 \mathrm{~h}$ after birth to screen for phenylketonuria. The remaining blood left after screening is stored on dried blood spots (DBS charts) in the Danish Neonatal Screening Biobank. Contemporary vitamin $\mathrm{D}$ analyses techniques can detect vitamin $\mathrm{D}$ concentration on the DBS charts ${ }^{(49)}$. Currently, our research group is conducting a case-control study which measures vitamin D levels in the blood on the DBS charts in a large populationbased sample of women diagnosed with pre-eclampsia, and randomly selected control women. Results of this study will be used to validate the findings of the present study. If our findings are confirmed by more robust study designs, this will have important public health implications because it will demonstrate a possibility of pre-eclampsia prevention by simple and affordable food fortification. Efforts to prevent pre-eclampsia are important, as the disease bears health risks for the mother and the offspring, and the only definite cure known so far is delivery ${ }^{(3)}$.

The biological mechanisms linking fetal vitamin D and later pre-eclampsia risk are most probably related to the maturity of the immune system. T-cell development and maintenance may be of importance in forming the adult immune system. A balance between helper T1 cytokines (Th1) and helper T2 cytokines (Th2) is necessary for an optimal immune system ${ }^{(50)}$. Vitamin D receptors are found on most immune cells, making hormonal vitamin $\mathrm{D}$ an important immune regulator stimulating Th2 expression and inhibiting Th1 expression ${ }^{(26,51)}$. An overexpression of Th1 response may be involved in the development of preeclampsia $^{(43,52)}$.

Several studies have reported that smoking in pregnancy reduces the risk of pre-eclampsia ${ }^{(53,54)}$. Smoking may interact with other risk and/or protective factors, including prenatal vitamin D level. Therefore, analyses differentiated by smoking status were used to investigate if small doses of extra vitamin D from food fortification affected pre-eclampsia risk. Indeed, we found that prenatal vitamin $\mathrm{D}$ intake seemed to be a protective factor in currently smoking pregnant women (i.e. women who smoked during pregnancy benefited most from extra vitamin D intake during their own gestation). The fact that the women exposed to extra vitamin D during fetal life were more often smokers should not bias our results, as they smoked while being pregnant, and exposure to vitamin D occurred during the pregnant women's own fetal development. Exposure to smoking during fetal life (i.e. smoking status of the mothers of the studied women) was not recorded. Importantly, although smoking is associated with a lower risk of pre-eclampsia ${ }^{(45,46,55)}$, smoking is also associated with several adverse perinatal outcomes and should never be promoted to reduce the risk of pre-eclampsia.

\section{Strengths and limitations}

The use of a societal experiment design to study an association between exposure to extra vitamin D during fetal life and later risk of pre-eclampsia has both strengths and limitations. The design determined the sampling, exposure measurement and possible confounding. In our design, period of birth approximated prenatal exposure to extra vitamin D from the fortified margarine. As the fortification programme was cancelled in 1985, we analysed women from adjacent birth cohorts born around 1985. We knew the exact date of the cancellation of the fortification programme and therefore we could define precise exposure and non-exposure periods for the adjacent national birth cohorts. As the birth cohorts were very close to each other and covered a narrow time period, we considered all the characteristics of our study population, except for prenatal exposure to vitamin $\mathrm{D}$ fortification, to be randomly distributed between exposed and unexposed individuals; thus, confounding was not expected. To exemplify our reasoning in regard to a low social status as a potential confounder for pre-eclampsia ${ }^{(56)}$, the following arguments can be provided. The study population covers all births, i.e. from all social strata, retrieved from the national Danish medical registries including all Danes. Maternity care in Denmark is free of charge and all pregnant women, i.e. irrespective of social status, are followed by a standardized protocol of prenatal care and are consequently registered into the national Danish medical registries. Thus, we assume that all social strata are equally represented in both groups.

The confounding in our design, however, could occur if secular changes in alternative exposure sources (i.e. vitamin D intake via food or exposure to bright sunshine), outcomes (i.e. pre-eclampsia incidence) and potential confounders (e.g. mother's socio-economic status and smoking, mother's exposure to infections and physical activity) were taking place in Denmark during 1983-1988, a narrow time period covering our exposed and unexposed birth cohorts. Consequently, the limitation of the societal experiment design is that it assumes that in the period analysed, there were no other changes except the one of interest. We could not identify such secular changes in our study. Nevertheless, we acknowledge that some secular changes where evidence is difficult or impossible to document may have occurred. For example, women born in 1983-1985 may have been slightly less exposed to 
maternal smoking (or exposure to smoking in fetal life), compared with women born in 1986-1988, as since the 1970s all pregnant women in Denmark were advised to stop smoking ${ }^{(57)}$ and studies suggest that smoking during pregnancy is declining ${ }^{(58,59)}$. We were unable to get information on smoking habits of the mothers of our study population, as smoking habits were not recorded into the MBR until $1997^{(60)}$. Moreover, in the period 1987-1988 changes occurred in the Danish fiscal policy aiming at reducing household expenditure ${ }^{(61)}$. A change towards a healthier self-reported diet in the Danish population during 1985-2001 was also noted ${ }^{(62,63)}$. Thus, there could have been confounding which we did not consider.

We did, however, consider alternative exposures to vitamin D around 1985: changes in fortified margarine intake in 1983-1988; changes in vitamin D supplement recommendations for pregnant women; and women's exposure to bright sunshine hours during the same period. Food disappearance statistics showed that the change in margarine consumption in the period analysed was minimal: from $16.9 \mathrm{~kg} / \mathrm{capita}$ in 1983 to $16.2 \mathrm{~kg} /$ capita in 1985 and $17.0 \mathrm{~kg} / \mathrm{capita}$ in $1988^{(47)}$. Vitamin D supplementation during pregnancy recommendations did not change during 1983-1988. Therefore, we assume that the overall alternative fetal exposure to vitamin D from foods was comparable in both groups. Further, differences in monthly bright sunshine hours per year during 1983-1988 were not significant. Amounts of bright sunshine hours during gestation, compared between the individuals in exposed and unexposed cohorts, were however significantly different, and ideally should have been adjusted for in our analyses ${ }^{(64,65)}$.

The main strength of the present large-scale study is the use of data from the Danish nationwide medical registries. The Danish national administrative and medical registers are considered to have high completeness and good validity. A high degree of validity of the ICD-10 pre-eclampsia diagnoses in the DNPR has been confirmed by comparing diagnoses of pre-eclampsia from the registry with standardized phone interviews in a study carried out between 1998 and 2002 that included a total of 3039 pregnancies $^{(66)}$. However, the coding of the diagnoses gestational hypertension and pre-eclampsia included other serious diseases and may have introduced non-differential misclassification errors causing a disappearance of the observed association $^{(67)}$. The lower gestational age at delivery observed in older women supports the validity of the data from the MBR, as it reflects national guidelines for earlier induction of labour in post-term pregnancies in Denmark in $2009^{(42)}$. As the present study is based on information retrieved from the Danish national health registries collected independently of the study, selection and information bias are considered to be negligible. The registers, however, contain no information on the smoking status of the mothers of the women in our study population, which may be considered a potential limitation in our analyses.

\section{Conclusion}

The results of our study suggest that small extra doses of vitamin D from food fortification during fetal development may decrease the risk of developing pre-eclampsia during first pregnancy in adulthood. The beneficial effect of the extra vitamin D during fetal development appears to be particularly protective against pre-eclampsia for women who smoke during pregnancy.

\section{Acknowledgements}

Financial support: This study was funded by the Danish Agency for Science, Technology and Innovation, the Ministry of Science, Higher Education, under the instrument 'Strategic Research Projects' (grant previous 11-116213 now 0603-00453B) and by the PhD School of Faculty of Health Sciences the University of Southern Denmark. The funders had no role in the design, analysis or writing of this article. Conflict of interest: None. Authorship: B.L.H. conceived the research idea; M.S. and B.L.H. designed the research; M.S. performed the statistical analysis; M.S., P.D., P.F., R.H. and B.L.H. interpreted the results; M.S. drafted the manuscript and P.D., P.F., R.J. and B.L.H. commented on it; M.S. and B.L.H. had primary responsibility for the final content. All authors read and approved the final manuscript. Ethics of human subject participation: Access and linkage permission was obtained from the Danish Data Protection Agency (journal number 2012-41-1156). The study was based on already collected data which by Danish law do not need ethical approval.

\section{Supplementary material}

To view supplementary material for this article, please visit https://doi.org/10.1017/S1368980017003135

\section{References}

1. James PR \& Nelson-Piercy C (2004) Management of hypertension before, during, and after pregnancy. Heart $\mathbf{9 0}$, 1499-1504.

2. American College of Obstetricians and Gynecologists, Task Force on Hypertension in Pregnancy (2013) Hypertension in pregnancy. Report of the American College of Obstetricians and Gynecologists' Task Force on Hypertension in Pregnancy. Obstet Gynecol 122, 1122-1131.

3. Mol BW, Roberts CT, Thangaratinam S et al. (2016) Preeclampsia. Lancet 387, 999-1011.

4. Hernandez-Diaz S, Toh S \& Cnattingius S (2009) Risk of preeclampsia in first and subsequent pregnancies: prospective cohort study. BMJ 338, b2255.

5. Skjaerven R, Wilcox AJ \& Lie RT (2002) The interval between pregnancies and the risk of preeclampsia. $N$ Engl J Med 346, 33-38.

6. Tranquilli AL, Dekker G, Magee L et al. (2014) The classification, diagnosis and management of the hypertensive 
disorders of pregnancy: a revised statement from the ISSHP. Pregnancy Hypertens 4, 97-104.

7. Chen CW, Jaffe IZ \& Karumanchi SA (2014) Pre-eclampsia and cardiovascular disease. Cardiovasc Res 101, 579-586.

8. Henry EB, Patterson CC \& Cardwell CR (2011) A metaanalysis of the association between pre-eclampsia and childhood-onset type 1 diabetes mellitus. Diabet Med 28, 900-905.

9. Wu CS, Nohr EA, Bech BH et al. (2011) Diseases in children born to mothers with preeclampsia: a population-based sibling cohort study. Am J Obstet Gynecol 204, 157.e1-e5.

10. Say L, Chou D, Gemmill A et al. (2014) Global causes of maternal death: a WHO systematic analysis. Lancet Glob Health 2, e323-e333.

11. Alsnes IV, Janszky I, Forman MR et al. (2014) A populationbased study of associations between preeclampsia and later cardiovascular risk factors. Am J Obstet Gynecol 211, 657. e1-e7.

12. Williams PJ \& Broughton Pipkin F (2011) The genetics of pre-eclampsia and other hypertensive disorders of pregnancy. Best Pract Res Clin Obstet Gynaecol 25, 405-417.

13. Autier P, Boniol M, Pizot C et al. (2014) Vitamin D status and ill health: a systematic review. Lancet Diabetes Endocrinol 2, 76-89.

14. Roberts JM, Bodnar LM, Patrick TE et al. (2011) The role of obesity in preeclampsia. Pregnancy Hypertens 1, 6-16.

15. Cavazos-Rehg PA, Krauss MJ, Spitznagel EL et al. (2015) Maternal age and risk of labor and delivery complications. Matern Child Health J 19, 1202-1211.

16. Jaskolka D, Retnakaran R, Zinman B et al. (2016) Fetal sex and maternal risk of pre-eclampsia/eclampsia: a systematic review and meta-analysis. BJOG 124, 553-560.

17. Alpoim PN, Godoi LC, Pinheiro Mde B et al. (2016) The unexpected beneficial role of smoking in preeclampsia. Clin Chim Acta 459, 105-108.

18. Wikstrom AK, Stephansson O \& Cnattingius S (2010) Tobacco use during pregnancy and preeclampsia risk: effects of cigarette smoking and snuff. Hypertension 55, 1254-1259.

19. De-Regil LM, Palacios C, Lombardo LK et al. (2016) Vitamin D supplementation for women during pregnancy. Cochrane Database Syst Rev issue 1, CD008873.

20. Hypponen E, Cavadino A, Williams D et al. (2013) Vitamin $\mathrm{D}$ and pre-eclampsia: original data, systematic review and meta-analysis. Ann Nutr Metab 63, 331-340.

21. Barker DJ, Eriksson JG, Forsen T et al. (2002) Fetal origins of adult disease: strength of effects and biological basis. Int J Epidemiol 31, 1235-1239.

22. Hart PH, Lucas RM, Walsh JP et al. (2015) Vitamin D in fetal development: findings from a birth cohort study. Pediatrics 135, e167-e173.

23. Petersen SB, Olsen SF, Molgaard C et al. (2014) Maternal vitamin $\mathrm{D}$ status and offspring bone fractures: prospective study over two decades in Aarhus City, Denmark. PLoS One 9, e114334

24. Milman N, Hvas AM \& Bergholt T (2012) Vitamin D status during normal pregnancy and postpartum. A longitudinal study in 141 Danish women. J Perinat Med 40, 4.

25. Perni UC, Wikstrom AK, Cnattingius $S$ et al. (2012) Interpregnancy change in smoking habits and risk of preeclampsia: a population-based study. Am J Hypertens 25, 372-378.

26. Hypponen E, Hartikainen AL, Sovio U et al. (2007) Does vitamin D supplementation in infancy reduce the risk of pre-eclampsia? Eur J Clin Nutr 61, 1136-1139.

27. Thurner S, Klimek P, Szell M et al. (2013) Quantification of excess risk for diabetes for those born in times of hunger, in an entire population of a nation, across a century. Proc Natl Acad Sci U S A 110, 4703-4707.
28. Lumey LH, Stein AD \& Susser E (2011) Prenatal famine and adult health. Annu Rev Public Health 32, 237-262.

29. Haraldsdóttir J, Holm L, Jensen JH et al. (1986) Danish Dietary Habits 1985 - 1. The Main Results. Copenhagen: Levnedsmiddelstyrelsen.

30. Minister of Agriculture and Fishing (1937) Act no. $1437 / 5$ 1937 supplementing the act no. 95 of 1 April 1925 for manufacturing and marketing of margarine. Danish Law Gazette A, 805-807.

31. Minister of Agriculture and Fishing (1937) Ministerial order no. 229 28/7 1937 on manufacture and marketing of margarine etc. Danish Law Gazette A, 1361-1368.

32. Ministry of Environment and Food (1985) Ministerial order no. $19620 / 51985$ of entry into force of the law on margarine etc. Danish Law Gazette A, 1-9.

33. Ministry of Environment and Food (1985) Ministerial order no. 197 20/5 1985 on margarine etc. Danish Law Gazette A, $1-9$.

34. Pedersen CB (2011) The Danish Civil Registration System. Scand J Public Health 39, 7 Suppl, 22-25.

35. Knudsen LB \& Olsen J (1998) The Danish Medical Birth Registry. Dan Med Bull 45, 320-323.

36. Lynge E, Sandegaard JL \& Rebolj M (2011) The Danish National Patient Register. Scand J Public Health 39, 7 Suppl., 30-33.

37. Cole TJ, Bellizzi MC, Flegal KM et al. (2000) Establishing a standard definition for child overweight and obesity worldwide: international survey. BMJ 320, 1240-1243.

38. Cole TJ, Flegal KM, Nicholls D et al. (2007) Body mass index cut offs to define thinness in children and adolescents: international survey. BMJ 335, 194.

39. Jeyabalan A (2013) Epidemiology of preeclampsia: impact of obesity. Nutr Rev 71, Suppl. 1, S18-S25.

40. Uzan J, Carbonnel M, Piconne O et al. (2011) Pre-eclampsia: pathophysiology, diagnosis, and management. Vasc Health Risk Manag 7, 467-474.

41. Bartsch E, Medcalf KE, Park AL et al.; High Risk of Preeclampsia Identification Group (2016) Clinical risk factors for pre-eclampsia determined in early pregnancy: systematic review and meta-analysis of large cohort studies. BMJ 353 , i1753.

42. Hedegaard M, Lidegaard O, Skovlund CW et al. (2015) Perinatal outcomes following an earlier post-term labour induction policy: a historical cohort study. BJOG 122, $1377-1385$.

43. Sibai B, Dekker G \& Kupferminc M (2005) Pre-eclampsia. Lancet 365, 785-799.

44. Hypponen E, Laara E, Reunanen A et al. (2001) Intake of vitamin D and risk of type 1 diabetes: a birth-cohort study. Lancet 358, 1500-1503.

45. Jaaskelainen T, Knekt P, Marniemi J et al. (2013) Vitamin D status is associated with sociodemographic factors, lifestyle and metabolic health. Eur J Nutr 52, 513-525.

46. Thuesen B, Husemoen L, Fenger M et al. (2012) Determinants of vitamin D status in a general population of Danish adults. Bone 50, 605-610.

47. Fagt S (2001) The Supply of Food in 1955-1999. The Development in the Danish Diet - Consumption, Purchasing and Habits. Copenhagen: The Food Administration.

48. Jacobsen R, Hypponen E, Sorensen TI et al. (2015) Gestational and early infancy exposure to margarine fortified with vitamin D through a national Danish programme and the risk of type 1 diabetes: the D-Tect Study. PLoS One 10, e0128631.

49. Norgaard-Pedersen B \& Hougaard DM (2007) Storage policies and use of the Danish Newborn Screening Biobank. $J$ Inherit Metab Dis 30, 530-536.

50. Mora JR, Iwata M \& von Andrian UH (2008) Vitamin effects on the immune system: vitamins A and D take centre stage. Nat Rev Immunol 8, 685-698. 
51. Jonsson Y, Matthiesen L, Berg G et al. (2005) Indications of an altered immune balance in preeclampsia: a decrease in in vitro secretion of IL-5 and IL-10 from blood mononuclear cells and in blood basophil counts compared with normal pregnancy. I Reprod Immunol 66, 69-84.

52. Hypponen E (2005) Vitamin D for the prevention of preeclampsia? A hypothesis. Nutr Rev 63, 225-232.

53. Conde-Agudelo A, Althabe F, Belizan JM et al. (1999) Cigarette smoking during pregnancy and risk of preeclampsia: a systematic review. Am J Obstet Gynecol 181, 1026-1035.

54. England L \& Zhang J (2007) Smoking and risk of preeclampsia: a systematic review. Front Biosci 12, 2471-2483.

55. Brot C, Jorgensen NR \& Sorensen OH (1999) The influence of smoking on vitamin D status and calcium metabolism. Eur J Clin Nutr 53, 920-926.

56. Silva LM, Coolman M, Steegers EA et al. (2008) Low socioeconomic status is a risk factor for preeclampsia: the Generation R Study. J Hypertens 26, 1200-1208.

57. National Board of Health Committee for Health Education (1977) Pregnancy, Childbirth, Infant Care. Guidance to Parents. Copenhagen: National Board of Health.

58. Ekblad M, Gissler M, Korkeila J et al. (2014) Trends and risk groups for smoking during pregnancy in Finland and other Nordic countries. Eur J Public Health 24, 544-551.

59. Wisborg K, Henriksen TB, Hedegaard M et al. (1996) Smoking among pregnant women and the significance of sociodemographic factors on smoking cessation. Ugeskr Laeger 158, 3784-3788.
60. Mattsson K, Kallen K, Rignell-Hydbom A et al. (2015) Maternal smoking during pregnancy and daughters' preeclampsia risk. PLoS One 10, e0144207.

61. Ministry of Taxation (2001) Three Reforms of Personal Taxes 1987-2002. Copenhagen: Ministry of Taxation.

62. Fagt S, Matthiesen J, Biltoft-Jensen A et al. (2004) Developments in the Danish Diet 1985-2001 - with a Focus on Sugar and Alcohol as Well as Motivation and Barriers to a Healthy Lifestyle. Copenhagen: Danish Institute for Food and Veterinary Research.

63. Osler M, Heitmann BL \& Schroll M (1997) Ten year trends in the dietary habits of Danish men and women. Cohort and cross-sectional data. Eur J Clin Nutr 51, 535-541.

64. Jacobsen R, Moldovan M, Vaag AA et al. (2016) Vitamin D fortification and seasonality of birth in type 1 diabetic cases: D-tect study - ERRATUM. J Dev Orig Health Dis 7, 429.

65. Jacobsen R, Frederiksen P \& Heitmann BL (2016) Exposure to sunshine early in life prevented development of type 1 diabetes in Danish boys. J Pediatr Endocrinol Metab 29, 417-424.

66. Klemmensen AK, Olsen SF, Osterdal ML et al. (2007) Validity of preeclampsia-related diagnoses recorded in a national hospital registry and in a postpartum interview of the women. Am J Epidemiol 166, 117-124.

67. Grimes DA \& Schulz KF (2002) Bias and causal associations in observational research. Lancet 359, 248-252. 